revista ANTHROPOLÓGICAS

Ano 24, 31(1): 249-277, 2020

\title{
Duplos Funerais: quando a morte encontra o morto em contextos transnacionais
}

\author{
Mísia Lins Reesink ${ }^{a}$ \\ Andrea D. Martins ${ }^{\mathrm{b}}$ \\ Jéssica Greganich ${ }^{c}$
}

$\mathrm{Na}$ literatura antropológica são poucas as análises etnográficas sobre o fenômeno da morte em contextos transnacionais, apesar da antropologia ser uma das ciências sociais que mais tem refletido sobre a morte. Buscando diminuir esta lacuna, apresentamos aqui uma reflexão comparativa entre três diferentes situações de rituais de morte ocorridos em contextos transnacionais. A primeira situação acontece na Inglaterra entre imigrantes bengaleses, descrita pela antropóloga britânica Katy Gardner; a segunda ocorre no Suriname, sendo analisada por Ivon van der Pijl, antropóloga holandesa; a terceira, ocorrendo na Holanda, entre imigrantes brasileiros, tratando-se dos nossos dados de pesquisa. Com isso, procuramos identificar as distinções e aproximações entre os três diferentes casos, argumentando que, em determinados contextos transnacionais, no advento da morte de um migrante, através da performance de parte de familiares e/ou comunidades, instaura-se o que aqui problematizamos e categorizamos como o ritual de 'duplo funeral'.

Duplos funerais, Comparação, Morte, Transnacionalismo, Migração.

Não é muito comum encontrar na literatura antropológica análises e descrições etnográficas sobre o fenômeno da morte em contextos

a Professora do Departamento de Antropologia e Museologia e da Pós-Graduação em Antropologia (UFPE). Email: emreesink@gmail.com.

b Pesquisadora do Devir (UFPE) e pesquisadora independente na Holanda. Possui Pós-Doutorado no PPGA-UFPE (PNPD-CAPES). Email: adamacena@hotmail.com.

c Doutora em Antropologia (UFRGS/VU-Amsterdam), com Pós-Doutorado no PPGA-UFPE (PNPD-CAPES). Email: greganich@hotmail.com. 
transnacionais, apesar de ser a antropologia uma das ciências sociais que, historicamente, mais tem refletido sobre este fenômeno (p. ex.: Hertz 1907; Van Gennep 1909; Fabian 1972; Thomas 1975; Bloch \& Parry 1982; Rodrigues 1983; Metcalf \& Huntington 1992; Reesink 2016 e 2003) ${ }^{1}$. Este artigo se propõe a contribuir no acúmulo do conhecimento antropológico sobre esse fenômeno específico. Para isto, pretendemos apresentar aqui uma reflexão comparativa sobre diferentes 'modelos' construídos a partir de situação rituais de morte em contextos transnacionais, incluindo os dados da nossa pesquisa de campo realizada na Holanda. São quatro os 'modelos' identificados, dos quais apenas três serão tratados na comparação.

O primeiro deles é a situação em que a morte e todo o complexo ritual funerário acontecem no lugar de moradia do morto em situação de migração: esse modelo de situação ritual é principalmente descrito no trabalho de Olwig (2009), em que a autora descreve os rituais fúnebres em uma comunidade migrante caribenha em Londres: a morte do imigrante ocorre no país de acolhimento, assim como todos os rituais fúnebres são aí realizados.

O segundo modelo de situação ritual pode ser descrito quando a morte ocorre no lugar de moradia (país de acolhimento), mas a parte principal dos rituais, incluindo o enterramento, é realizada no país de origem, havendo ainda uma distinção de gênero, em que as mulheres permanecem no país de acolhimento (mas, também, no de origem) sem participar da parte principal dos rituais. É no trabalho de Gardner (2002) sobre imigrantes bengaleses em Londres que podemos analisar essa realidade etnográfica. $\mathrm{O}$ terceiro modelo de situação ritual encontramos no trabalho de Pijl (2016), em que a autora descreve a morte de um imigrante surinamês radicado no Canadá que morreu longe do seu lugar de moradia, mas no seu país de origem, quando de uma visita em férias. Aqui, assim como a morte se deu no país de origem, também aí os principais ritos fúnebres foram realizados.

O quarto modelo ritual identificamos na análise dos dados da pesquisa realizada em Amsterdam (Holanda), junto à comunidade ca- 
tólica de língua portuguesa naquela cidade. Aqui se trata do evento da morte de uma criança brasileira, com mãe ilegal no país, em que a morte e os principais ritos fúnebres foram realizados no país de acolhimento, contudo a re-performance do 'enterramento' ocorreu no país de origem (Brasil).

Os três últimos modelos identificados de situações rituais fúnebres em contexto de migração transnacional apresentam distinções importantes, contudo, sugerem algo em comum, o que aqui avançamos como o evento do 'duplo funeral', e, ao que nos parece, ainda não discutido analiticamente pela literatura sobre morte em contextos transnacionais. Isto nos faz deter na análise comparativa destas três situações etnográficas, descartando o primeiro modelo contido no trabalho de Olwig.

Portanto, neste artigo, pretendemos analisar comparativamente as três situações etnográficas apresentadas no trabalho de Gardner, de Pijl e na descrição dos nossos dados etnográficos. Com isso, procuraremos identificar as distinções e aproximações entre os três diferentes casos, argumentando que, em determinados contextos transnacionais, no advento da morte de um migrante, familiares e ou comunidades realizão o que aqui chamamos de 'duplo ritual fúnebre'. Para isto, na primeira parte do trabalho, apresentaremos os dados de Gardner sobre os migrantes bengaleses em Londres; na segunda parte, apresentaremos os dados de Pijl para o acontecimento da morte de um migrante surinamês de passagem no Suriname; em seguida, faremos a descrição ritual da situação do evento da morte da criança brasileira imigrante em Amsterdam. Por fim, apresentaremos as nossas conclusões.

\section{Definição de 'duplos funerais'}

Antes, contudo, de iniciarmos mais precisamente a discussão, é necessário descrever ou, melhor dizendo, definir o que aqui chamamos de 'duplo funeral'. A primeira vista, poderia parecer que estamos aqui apenas apresentando uma versão do conceito pioneiramente apresentado por Hertz (1907) de 'segundo enterramento' (les doubles 
obsèques). Entretanto, o que observamos aqui é sensivelmente diferente do definido por ele.

Hertz está preocupado em analisar o fenômeno, encontrado em algumas sociedades (os seus dados são de povos asiáticos), de duas etapas nos ritos fúnebres, e que consiste em um 'primeiro enterramento' do corpo, em uma sepultura provisória - pouco tempo após o falecimento do sujeito; e, após cerca de um ano, a exumação desses restos mortais e o seu 'segundo enterramento', agora em uma sepultura definitiva. Fazendo uma correlação entre o estado da alma, do corpo e dos sobreviventes, Hertz avança que o primeiro período está diretamente relacionado à ideia de 'estado transitório' da condição da alma, do corpo e dos enlutados (período que tem uma semelhança importante com o conceito de margem-liminaridade de Van Gennep 1909): este período é simbolizado como etapa 'molhada'; o segundo período está ligado à ideia de 'estado permanente' da condição da alma, corpo e sobreviventes: neste caso, simbolizado como etapa 'seca'.

A prática do segundo enterramento tem sido descrita em diversas etnografias e campos etnográficos. Por exemplo, há os trabalhos de Carneiro da Cunha (1978) e de Chaumeil (1997) descrevendo esta prática entre povos indígenas da América do Sul. Também a pesquisa de Danforth (1982) que analisa este ritual entre uma comunidade grega; ou ainda, Reesink (2003) que comenta a prática do segundo enterramento no nordeste brasileiro (em caso de sepulturas rotativas, após dois anos os restos mortais são exumados e depositados definitivamente em um ossuário - anônimo ou individualizado). Mais recentemente, Moorselaar (2019) analisa as práticas rituais holandesas, envolvendo o destino das cinzas (asbesteming) originadas no ritual de cremação, à luz da teoria hertziana, considerando que aqui também encontramos um tema de 'sepultura' temporária (quando as cinzas devem permanecer por lei pelo menos um mês no crematório) e depois o destino final - 'sepultura' definitiva das cinzas do corpo.

Pode-se concluir, então, que no conceito apresentado por Hertz, e aplicados por pesquisadores em outros contextos, há a obrigato- 
riedade da presença do mesmo corpo em ambas as etapas e/ou sepultamentos. Trata-se, portanto, de uma relação 'íntima' entre os ritos e a presença material do corpo (etapa molhada e etapa seca do cadáver); assim como, trata-se de momentos distintos que integram o mesmo ritual.

Contrariamente a isto, o que define a ideia de 'duplos funerais' é, primeiramente, um contexto de migração transnacional; segundo, a impossibilidade de, do ponto de vista dos sobreviventes e suas diferentes perspectivas, os rituais serem feitos de maneira 'integrada' ou 'completa', em resposta as suas expectativas emocionais, morais, simbólicas e práticas; terceiro, a obrigação moral e emocional para alguns sobreviventes de 'completar' os ritos fúnebres; por último, a não obrigatoriedade (na maior parte das vezes, a impossibilidade) da presença do corpo ou partes do corpo morto em todos os ritos (o que não implica em dizer que não seja possível a sua presença, como veremos). Vejamos agora como esta definição pode ser aplicada nos três casos a seguir descritos e, por fim, analisados.

\section{Morte em Londres}

A primeira etnografia que iremos discutir, nesta comparação, é a realizada por Katy Gardner em seu artigo 'Death of a migrant: transnational death rituals and gender among Britsh Sylhetis' (2002). Trata-se de uma etnografia sobre situação de morte entre migrantes bengalêses oriundos da região de Sylhet (Bangladeshi). $O$ foco principal do artigo é na questão de gênero, em que a análise do que acontece quando Londoni ${ }^{2}$ morrem revela uma boa parte dos diferentes efeitos de se viver entre dois lugares em homens e mulheres ${ }^{3}$.

Um ponto importante na análise de Gardner é o ponto de vista a partir do grupo doméstico. Tomando como partida a afirmação de Sharma de que migração é um 'processo do grupo doméstico', o ciclo de desenvolvimento to grupo doméstico sendo um importante aspecto da migração, inclusive na questão do envio ou não de remittances e da performance de rituais no local de origem; contudo, não é o único 
aspecto. Assim, "os rituais e trocas que eu descrevo não são necessariamente limitadas ao grupo doméstico, mas incorpora a um corpo amorfo de vizinhos e parentes" (Gardner 2002:194).

Gardner parte do pressuposto que a morte e rituais fúnebres em contexto de migração possuem um custo emocional importante, com pesos diferentes entre homens e mulheres. $\mathrm{Ou}$, nas palavras da autora: "relatos de rituais fúnebres que ocorrem entre dois espaços indicam também os custos emocionais do transnacionalismo e como estes podem ser diferentes entre homens e mulheres, e entre velhos e jovens" (2002:192). Em especial, no caso da comunidade mulçumana bengalesa de Londres, em que, devido às especificidades de seus processos migratórios, essa comunidade encontra-se em situação sócio-econômica (e legal) difícil, com baixa integração das mulheres à sociedade inglesa, sobretudo, migrantes de primeira geração que migraram para reunir-se com maridos e/ou filhos.

A partir de uma contextualização mais ampla dessas dinâmicas, Gardner aponta que quando do evento da morte duas decisões podem ser tomadas: enterrar o corpo em um cemitério islâmico de Londres, ou trasladar o corpo para ser enterrado em Bangladesh. Esta última escolha foi tomada pela família de Abdul Wahed, casado com Soyun Nessa. Imigrantes de primeira geração, quando da morte de Abdul Wahed em Londres, seu corpo foi embalsamado e enviado para Sylhet para ser aí enterrado, acompanhado dos filhos masculinos, ficando Soyun Nessa e sua filha em Londres. As razões dadas para a permanência da viúva em Londres foi a de que seria necessário ela ficar para cuidar da filha doente ${ }^{4}$; contudo, Gardner constata que essa situação se repete frequentemente entre as bengalesas, em situações de traslados, tanto devido a questões econômicas, quanto às regras e rituais religiosos mulçumanos que prescrevem a reclusão em casa das viúvas por um período de quarenta dias. Enquanto regra, "em Sylhet, funerais são também o domínio ritual dos homens" (Gardner 2002:195), tendo em vista que no espaço público - segundo as regras mulçumanas - são os que têm a liderança, visibilidade e centralidade. 
Assim, no caso dos funerais de Abdul Wahed, estes "foram não apenas espalhados entre dois espaços, mas ainda com um forte conteúdo de gênero" (Gardner 2002:196).

Gardner avança ainda mais na sua discussão ao afirmar que o interesse particular no caso de funerais transnacionais é a ligação entre diferentes tipos a diferentes espaços. No caso particular que ela descreve, os rituais femininos são performados em Londres, enquanto os masculinos são realizados em Sylhet. Entretanto, a autora relativiza dizendo que "apesar de que certamente não gostaria de caracterizar cada espaço como em geral associado como ritual masculino ou feminino (pois, claro que que viúvas também performam rituais em Bangladeshi e homens enterram seus mortos em cemitérios islâmicos na Grã-Bretanha), esta divisão de trabalho ritual entre espaços é sugestiva para uma observação mais geral . Primeiro, para muitos Sylhets britânicos, a desh ${ }^{5}$ é fortemente associada ao capital sagrado. Segundo, homens têm mais oportunidades de aceder a este capital que mulheres" (Gardner 2002:196).

De qualquer forma, o que temos aqui é a realização de 'duplos funerais' ou mais precisamente, duplos funerais realizados pelos parentes e, nesse caso particular, devido às condições de duplos espaços, com a divisão de trabalho ritual entre homens e mulheres - isto do ponto de vista da parte do grupo doméstico que está em contexto de migração transnacional. Neste sentido, esta divisão de trabalho ritual não implica em que partes do ritual se fazem em um espaço e as outras partes no outro (contexto de migração - mulheres - ações rituais femininas/ local de origem - homens - ações rituais masculinas), construindo assim uma complementaridade. O que Gardner descreve são a sobreposição e inovação de ações rituais que ocorrem nos espaços diferentes, que aqui configuramos como fazendo parte de um tipo 'duplos funerais'.

Assim, Soyun Nessa, ao ficar em Londres, teve que se adaptar tanto ao contexto e regras do país hospedeiro quanto à ausência do corpo e do seu enterramento. A solução encontrada é uma recriação dos 
ritos tradicionais, incluindo o papel feminino aí desenvolvido, diante de um contexto diferente e desigual. Enquanto no país de origem, os funerais acontecem seguindo a formula tradicional, apesar da ausência de esposas e filhas; no país de acolhimento isto se torna impossível. Contudo, as mulheres procuram suprir os significados (culturais, emocionais, práticos, identitários) da ritualização da morte de um parente conjugando partes da ritualidade tradicional com as exigências do Estado. Contudo, segundo o que aponta Gardner, do ponto de vista simbólico e emocional, nem sempre este 'duplo funeral' parece ser suficiente. Como descreve a autora: "Apesar da exclusão dos rituais fúnebres em Sylhet, ela foi capaz de performar algum ritual de luto na Grã-Bretanha, apesar de que hoje em dia ela diz que sua incapacidade de acompanhar o corpo do esposo, ou de ver onde o corpo foi enterrado, é causa de grande tristeza para ela" (Gardner 2002:196).

\section{Morte em Suriname}

A segunda etnografia é a escrita por Pijl em seu texto 'Death in the family revisited: ritual expression and controversy in a Creole transnational mortuary sphere' (2016). Neste trabalho, a autora desenvolve uma análise do funeral de Orlando, surinamês que há mais de trinta anos tinha emigrado para o Canadá, e que vem a falecer repentinamente em Paramaribo, durante visita de férias. Residente na cidade de Toronto, motivado pelas comemorações de 25 anos de independência colonial do país vem visitar sua terra natal, parentes e amigos. Porém, após 24 horas da sua chegada sofre um infarto fulminante. A morte, abrupta e inesperada no Suriname gera controvérsias e conflitos, pois os parentes reagem diferentemente e atribuem sentidos e explicações diversas à sua morte por ter ocorrido na terra natal e não no Canadá, terra de imigração.

O ponto principal da análise de Pijl centra-se no argumento de que os eventos de morte são também "ocasiões que expressam controvérsias e falhas, especialmente em um contexto transnacional”, avançando que "especialmente na atualidade rituais fúnebres trans- 
nacionais frequentemente expressão mais tensão do que contribuição para a solidariedade e restauração do tecido social" (2016:149). Nesse sentido, para ela, em contextos transnacionais, o lugar e o tempo em que se morre ganha sentido particular. A análise dos rituais de morte nestes contextos demonstra que eles apresentam uma polifonia de sentidos em conexão à maneira como cada parente elabora a perda e vive o luto. "Quão trágica ou má foi de fato sua [de Orlando] morte, e para quem? Parentes respondem em diferentes maneiras à mortes súbitas, procurando explicações e sentidos da perda súbita e localizando a morte em uma biografia em marcha, ou seja: suas próprias biografias" (2016:148), acrescentando que "o exame desta morte na família levanta questões relativas à localização da morte como uma preocupação fundamental, e o que torna uma morte 'boa', 'má' ou 'trágica", e para quem" (2016:150).

$\mathrm{Na}$ etnografia realizada sobre os fatos envolvidos no evento da morte de Orlando, para a mãe, surinamesa, que sempre esperou o retorno do filho, o reeencontro e morte súbida são interpretados principalmente como cumprimento da "vontade de Deus". Como filho pródigo, ele voltou à casa materna, despediu-se dela pela última vez, ao encontrá-la imediantamente após chegar do aeroporto, e cumpre seu destino final: morrer na terra de origem. Para Lynn, esposa de Orlando, também imigrante no Canadá, mas de origem de Trinidade e Tobago, a narrativa do 'retorno do filho pródigo' é inaceitável, pois invisibiliza sua posição de esposa, anulando sua dor de perder o marido. Se há um consolo para as irmãs e mãe nesta narrativa, que representa o reencontro da família no Suriname, para Lynn o marido faleceu em terras estrangeiras, já que amigos e parentes canadenses próximos não fazem parte dos rituais de despedida. Sobretudo, ela expressa dúvidas de que o Suriname possa ainda ser considerado a terra natal do marido. Há mais de 30 anos vivendo no Canadá, seus planos depois da aposentadoria não eram de retorno ao Suriname, mas incluía outros destinos. Ela, por sua ve, sente-se pouco ligada aos familiares e ao Suriname. Portanto, segundo a autora, o caso evi- 
dencia que a morte assim como a vida está multisituada e incluí uma sobreposição do sentido de casa e pertença. Nas palavras da autora: "Logo após a morte de Orlando, ficou claro que a casa, apesar da sua conotação familiar, não é uma categoria autoevidente. Dessa forma, é necessário examinar com cuidado a dimensão espacial da morte e questionar a maneira em que noções de casa e pertencimento são empregadas" (Pijl 2016:154).

Ao destacar as disputas que envolvem a organização dos rituais de preparação do enterro, dentro da cultura criola, Pijl relembra também que tais rituais de passagens são dinâmicos e algumas vezes desestabilizam práticas estabelecidas, ao invés de representaram a afirmação de laços solidários no interior de um grupo ou cultura. O caso de Orlando manifesta como códigos culturais e interesses sociais tornam-se antagônicos, constituindo-se como um espaço de contestação social, pois "os enlutados claramente diferenciam nas suas crenças sobre a maneira como Orlando deveria ser comemorado e como se deveria realizar o luto" (Pijl 2016:155), complementando que os "rituais transicionais claramente demonstram como obrigações sociais, representações coletivas e orgulho público facilmente proporcionam conflitos com a individualidade, crenças pessoais, desejos e expressões" (2016:159). A autora argumenta, dessa forma, que os dados etnográficos refutam princípios funcionalistas e estruturalistas, bastantes presentes na literatura sobre o tema, que enfatizam aspectos de integração ou criação de maior solidariedade interna para a comunidade, a cultural local. As diversas narrativas sobre a história do morto, a multiplicidade de versões desparoquializa o sentido dos rituais de morte, segundo Pijl.

Isto é muito bem ilustrado no artigo pela descrição da situação da viúva Lynn, sendo o mais importante para a nossa reflexão. Como dito, 'despossuída' do corpo do morto, Lynn teve que se submeter à vontade da família, mesmo que contrariasse suas crenças, valores, práticas e sentidos de 'casa'. Pijl descreve, assim, como para Lynn o os rituais, 'fora de casa', estavam incompletos, pois “certamente, os rituais finais não marcaram um encerramento para Lynn. Haveria 
outro serviço cerimonial 'de volta para casa em Toronto, sua casa também!', Lynn sublinhou algumas vezes. A maior parte dos rituais transicionais não a tinham confortado ou ajudado a lidar com sua nova identidade de viúva" (2016:161). De acordo com o que descreve a autora, a volta para 'casa' devolveu a viúva agência e controle sobre como ritualizar sua perda, gerenciar sua memória e construir sua identidade enquanto viúva.

O artigo de Pijl não avança muito na questão dos 'duplos funerais', mesmo porque não era o objetivo da autora. Contudo, assim como o de Gardner, ele nos permite entrever como sujeitos, diante de eventos incontroláveis em torno da morte de um parente, procuram estabelecer algum controle naquilo que eles consideram importante para a performance de uma ritualização completa, ou poderíamos até interpretar como 'corretas', para dar conta tanto daquilo que seriam os anseios do morto como dos enlutados. Neste sentido, em contexto de migrações e mortes transnacionais, o 'duplo funeral', que analisamos aqui, é posto em marcha.

\section{Morte em Amsterdam}

Os imigrantes lusófonos católicos na Holanda (brasileiros, portugueses e africanos oriundos dos PALOP - Países Africanos de Língua Oficial Portuguesa ${ }^{6}$ ) compõem três comunidades nas paróquias de Amsterdam, Den Haag e Rotterdam, que se encontram para participar de missas e celebrações em português: na estrutura da Igreja Católica Holandesa - seguindo regulamentos do Vaticano - há a presença de comunidades linguísticas que, dentro das paróquias, tem espaço e certa autonomia para praticar o catolicismo em suas respectivas línguas, como as comunidades de língua espanhola, língua inglesa e língua portuguesa (Martins 2012; Reesink 2015 e 2018). Particularmente, no caso dos imigrantes católicos lusófonos, essas comunidades ligadas às paróquias constituem redes de relações sociais e de apoio entre migrantes, tanto aqueles que possuem os 'papéis' que permitem estadia legal a estes imigrantes, quanto aqueles que entram e perma- 
necem de forma ilegal no país. Dependendo do tipo de imigração (se 'comunitária' ou 'afetiva'7) e do tipo de status do imigrante (legal ou ilegal), a participação nessas comunidades pode ser mais permanente ou inconstante ou temporária.

Essas comunidades católicas são importantes para os imigrantes do ponto de vista da 'comunhão entre católicos', ou seja: da participação das atividades religiosas, e não menos fundamental (ou mesmo o mais vital), performadas na língua materna, o português (Reesink 2015). Ao lado disto, está a importância do caráter solidário dessas comunidades, que constroem uma rede de apoio social, que dão suporte emocional, prático e - muitas vezes - econômico aos imigrantes em situação precária e/ou ilegal. Um momento particular em que a comunidade se movimenta para dar apoio tanto religioso, emocional quanto prático e econômico, é em situações de falecimento.

O falecimento em contextos de migração, como analisamos nesta discussão, envolve não apenas o 'drama social' (Turner 1980) da morte em si mesmo, mas todos os elementos complicadores como regras, tradições e burocracias estranhas as experiências da maior parte dos imigrantes, em especial para o caso de ilegais, que estão em situações de maior fragilidade. Este é o caso particular que vamos analisar aqui, a morte de uma criança de 5 anos, que junto com sua mãe, morava a um ano na Holanda como imigrante ilegal. Este evento foi o que nos levou a refletir e abordar a questão da morte em contextos de migração transnacional a partir da possibilidade (ou do imperativo) da instauração e performance de 'duplos funerais'.

Kauane $^{8}$ morreu no domingo, dia 09 de julho de 2017, por afogamento na prainha de Sloterplas, em Amsterdam. Kauane, que nasceu em Porto Seguro (BA), era filha de pais brasileiros. A menina morava a pouco mais de um ano na Holanda, com Jiliane, sua mãe, e o padrasto. No Brasil, ela era criada e educada pela avó até os seus quatro anos de vida. A situação da mãe e filha era a de 'sem documentos', enquanto o padrasto gozava de status legal no país. Mãe e filha tinham planos de regressar definitivamente ao Brasil, em setembro. Embora, 
Wanusa, amiga de Jiliane, observe que muitos brasileiros dizem isso, mas "a situação de ser pobre aqui e lá no Brasil é muito diferente. Por isso, muita gente, volta [para cá] depois de um certo tempo" (Wanusa, brasileira, comunidade católica de língua portuguesa em Amsterdam, participante do grupo carismático Servos do Amor).

$\mathrm{O}$ trágico acidente aconteceu durante a estação do verão holandês, época em que as pessoas acorrem em grande número para os parques, praias e outros locais de diversão ao ar-livre, em especial em dias livres de muito sol. Na tarde daquele domingo, Kauane estava com a família e amigos na prainha de Sloterplas, e, como é comum nesse período do ano, o local estava cheio de frequentadores. Quando a mãe perdeu a filha de vista, passou a procurá-la na parte da areia, não imaginando que ela pudesse ter entrado na água. Assim que se deram conta do fato, foram acionados polícia e bombeiros, que resgataram rapidamente a menina da água; conseguiram reanimá-la nos primeiros socorros, contudo a menina chegou sem vida ao hospital.

$\mathrm{Na}$ Holanda, a mais recente lei que disciplina os cuidados com o cadáver é a Wet op de Lijkbezorging, de 1991, com alterações incluídas em 1998 e 2009 (Moorselaar 2019; Heessels 2012). Esta lei regula tanto os rituais de enterramento (begrafenis) quanto de cremação (crematie), assim como a declaração de causa mortis. Como em outros países europeus e cristãos, nos Países Baixos a tradição maior era de se enterrar o corpo, sendo a cremação autorizada no país por volta de 1915. A partir deste período, foi introduzido o termo 'uitvaart', que engloba os dois termos anteriores 'begrafenis' e 'crematie' (Cappers 2014). Apesar de existir a possibilidade e autorização de cremação deste o início do século 20, apenas nos anos 50 do século passado é que a cremação foi finalmente legalizada e regulamentada na Holanda. Segundo dados recentes, no século 21 , cerca de $60 \%$ dos holandeses são cremados (Heessels 2012).

Segundo a Wet op de Lijkbezorging, quando uma pessoa morre, a lei indica um período em que o falecido deve ser enterrado ou cremado. O tempo mínimo, após a declaração oficial do médico, é o de 
36 horas; e o tempo máximo para ser enterrado ou cremado é o de seis dias úteis depois de declarado morto (Moorselaar 2019; Heessels 2012), o que pode ser prolongado, por causa dos dias do fim de semana, até um total de nove dias. Em ocasiões especiais, este termo pode ser excedido: por exemplo, por questões religiosas ou porque membros da família, residentes em um país distante, querem participar do funeral. A permissão deve ser concedida oficialmente pelo governo (local).

Este tempo estipulado para os funerais, segundo Cappers (2014), está diretamente relacionado ao período de medische zekerheid (certeza médica) e a medische cultuurschap (cultura médica) na Holanda, que são complementares: trata-se de busca pela certeza científica no que se refere à morte (de fato) e a causa mortis, que procura evitar, de um lado, os enganos de se enterrarem pessoas que pareciam estar mortos, mas que de fato ainda estavam vivas; de outro, garantir cada vez mais a expansão de medidas sanitárias e higiências que controlem possíveis 'contaminações' entre o corpo/ cadáver e os vivos, assim como eliminar a possibilidade de morte não natural.

Entre o tempo de declaração da morte e o enterramento ou cremação do corpo (ou seis dias úteis), ocorre o período conhecido em termos leigos como 'wake' ou 'avondwake' (que poderia ser traduzido por velório em português) e em termos técnicos como post-mortem interval (PMI), classificado por Moorselaar (2019) como o 'primeiro período' dos rituais fúnebres na Holanda'. Nesta primeira fase é quando acontece, de um lado: os 'rituais de oblação' (Thomas 1975; Reesink 2003), ou dos cuidados específicos com o cadáver; de outro, os rituais do velório; também, todos os assuntos legais, práticos e burocráticos relacionados com os preparativos para as cerimônias fúnebres.

Na Holanda, a maior parte dos ritos fúnebres são realizadas a partir de empresas fúnebres privadas (Uitvaartbedrijven), existindo atualmente tanto grandes empresas como profissionais autônomos: essas empresas passam por um controle rigoroso do estado, e os profissionais que aí atuam precisam ter uma formação específica para atuarem 
no ramo (Blok et al 2018). A iniciativa de escolher qual empresa cuidará da organização do funeral e de entrar em contado fica por conta da família, ou algum representante dela. Quando da morte da menina, foi o padrasto quem se responsabilizou pelas relações com instâncias oficiais, como o contrato com o crematório, entrada no hospital, etc. A participação preponderante do padrasto nestes momentos, segundo informantes, promoveu uma reaproximação do casal, que estavam vivendo separados na ocasião da morte da criança.

O evento da morte de Kauane produziu a questão de como pagar os custos envolvidos no funeral. A mãe, Jiliana, indocumentada trabalhava ilegalmente com limpeza e não tinha dinheiro para pagar as despesas médicas e o traslado do corpo. Foi neste momento que a comunidade de língua portuguesa da Paróquia de Nossa Senhora de Fátima, em Amsterdam, da qual mãe e filha participavam esporadicamente, se mobilizou para arrecadar dinheiro para custear as despesas, cujo total fora estimado em 20 mil euros, à epoca. Para este fim, foi criada uma comunidade no Facebook chamada 'Ajude-nos a ajudar', para mobilizar pessoas e arrecadar doações online para Jiliane. Também foi arrecadado dinheiro em uma caixa na igreja.

Além da arrecadação do dinheiro para os ritos fúnebres e traslado, uma das decisões tomadas também na ocasião foi a de pagar a passagem do pai da menina, que morava no Brasil, para assistir ao funeral. Isso foi possível, porque financeiramente houve uma grande contribuição de várias igrejas. Wanuza, que cedeu a conta bancária para o depósito das doações, conta que foram cerca de 23.000 Euros ao total. A funerária custou cerca de $6.000,00$, pois os donos eram da rede de relações do Pe. Thiago, o padre responsável pela comunidade de língua portuguesa da paróquia, que pediu a eles apoio para o caso. No Brasil também ocorreu uma mobilização, arrecadando dinheiro para a realização do passaporte de urgência do pai de Kauane, contribuição para a sua passagem aérea e algum dinheiro extra para as despesas. $\mathrm{O}$ pai consegui chegar dia 13 de julho em Amsterdam para se despedir da filha e participar da missa de corpo presente. 
Em princípio, a opção de Jiliane e da família era a de fazer o traslado da filha para a sua cidade natal, no estado da Bahia, e ali fazer o enterramento da menina, na presença de familiares e amigos. No final, contudo, o corpo foi cremado. Assim, a escolha pela cremação, de fato, não foi o que a mãe queria, pois preferia que o corpo fosse enterrado para o Brasil. Nas palavras de Wanuza: "cremar não é da nossa cultura". No entanto, os custos para o traslado eram cotados em torno de 20.000 Euros e, ao final, o padrasto decidiu e assinar o contrato com a funerária. Ele se viu obrigado a optar pela cremação, no valor de $6.000,00$, pois era o que podiam pagar no momento. Ao final, a mobilização das diversas igrejas e pela internet gerou mais fundos do que se esperava, mas era tarde demais para alterar o contrato com a funerária. A tomada dessa decisão pelo padrasto gerou muita dor e discussão na família e entre amigos próximos; a maior parte das críticas cabendo ao padrasto. Porém, pessoas da comunidade consideram que o padrasto reagiu de maneira responsável e correta, cumprindo o que era combinado.

Durante o período do velório, o corpo de Kauane foi velado em uma sala do crematório onde seria realizada a cremação, até o momento em que o corpo foi levado à igreja para a cerimônia da missa de corpo presente, para ser novamente levado de volta ao crematório. Todo o tempo do velório, a mãe permaneceu ao lado do corpo da filha, nos horários permitidos pela empresa (normalmente, os velórios são fechados à noite). Ela levou para a sala onde se encontrava o corpo os brinquedos favoritos da Kauane para estarem juntos com ela: uma boneca negra e alguns bichos de pelúcia, colocando-os depois no caixão. Também levou um saquinho de chocolate 'm\&ms', os favoritos da menina.

De uma maneira geral, na Holanda, é durante o 'wake' que a pessoa falecida é 'apresentada' em um caixão aberto, a menos que a causa da morte tenha levado à causa séria de não fazer isso. Os momentos de visitação, em sua maioria, são regulados pela empresa funerário, ou pelo serviço de uitvaartverzorgers; especialmente, aqueles que desejam 
visitar a família enlutada recebem a informação dos horários de visitação do corpo, com ou sem a presença de famíliares (normalmente, há algum familiar presente). O 'wake' pode ocorrer em uma sala especial no hospital, na funerária ou no crematório, sendo também é comum ocorrer em 'verzorgingstehuis' que é a 'casa para idosos' e neste local tem uma sala especial para isso. No término do período de velório, os caixões são fechados e, em princípio, não voltam a ser abertos.

No sábado, dia 15 de julho de 2017, às 13h, foi realizada a missa de corpo presente da menina brasileira Kauane. A missa foi performada metade em português e metade em holandês, pois havia muitos holandeses na cerimônia, patrões da mãe e do padrasto ${ }^{10}$.

A entrada da igreja estava enfeitada com dois cachos de balões brancos. Foram feitas camisetas pretas que diziam 'Kauane é um anjo'. A mãe, Nelma (a irmã da mãe, também imigrante), o padrasto e o pai da menina entraram na igreja carregando o caixão de cor branca, com os pés virados em sua ao altar. Em princípio, pelas regras holandesas, não é permitido abrir o caixão na missa de corpo presente, ou em qualquer outro tipo de ritual de despedida, após o seu fechamento depois do 'wake' (Blok et al 2018), contudo isso foi feito no caso de Kauane $^{11}$. O caixão foi colocado na frente do altar e aberto para que as pessoas pudessem se despedir, dizer o ultimo adeus a Kauane, prestar condolências aos parentes e colocar flores. A romaria em frente ao caixão durou cerca de trinta minutos. Depois disto, foi iniciada a missa de corpo presente, quando o caixão permaneceu aberto durante toda a cerimônia, iniciada por uma oração cantada em conjunto ${ }^{12}$.

A missa de corpo presente, na Holanda (assim como em outros lugares $)^{13}$, difere um pouco em todas as igrejas e, às vezes, até por cerimônia, mas a base deve ser sempre a mesma. Dependendo do dia do ano, da ocasião e da história das narrativas bíblicas, as orações cantadas podem variar. Além disto, pode haver ou não comunhão, ou seja: a missa de corpo presente (quando há o momento da eucaristia), na realidade, pode se tratar de fato de uma celebração, quando não há o ritual da eucaristia e/ou quando não é realizada por um sacerdote ${ }^{14}$. 
Talvez por se tratar de uma criança, menor de sete anos e ainda não crismada, na missa de corpo presente de Kauane não foi realizado o momento da comunhão, apesar da presença de um sacerdote. Durante a cerimônia, entre as orações, Kauane foi homenageada em oração, com um telão onde passavam fotos da menina e dela com a família. Cercado pela fumaça do incenso do ato de incensar o caixão, o padre Thiago espargiu com água benta o corpo de Kauane. A cerimônia foi acompanhada pelo coro da igreja e todas as orações foram cantadas com todos de pé.

Dando um toque de ecumenismo ao momento, o pastor Marcos Viana, da Comunidade Cristã de Amsterdam, estava presente e declamou uma poesia, composta por ele especialmente para Kauane e seus familiares. Ele disse, muito emocionado e contendo as lágrimas, que o poema foi se formando na mente e no coração dele, desde o primeiro momento que recebeu a notícia do que acontecera.

O Segredo do Cedo, o Medo, o Tarde e a Verdade: A hora que o sol nasce tudo é lindo/É muito cedo/E ele é sempre bem-vindo/ Isto nos revela um segredo/Quando uma flor abre o botão/É bem cedo/Chama para si toda a atenção/De novo se manifesta um segredo/Quando a água brota/É muito cedo/Se esconde numa grota/De novo aqui o segredo/Quando uma viagem começa/É muito cedo/Se o caminho nos prega uma peça [...] Chegou mais cedo/Tem um ótimo tom/Tem verso tem prosa tem enredo/Mas tem algo que chega antes/Algo que chega cedo/Que muda tudo em instantes/E traz consigo o medo/Quando alguém parte para sempre/E isso acontece muito cedo/E infinita a dor que se sente/E isso carrega consigo o medo/Nessa hora se apresenta o Tarde/ Trazendo a culpa/E reclamando ser a verdade/Que entristece e insulta/O medo passa a ser desespero/Aí tudo fica tarde/De ultimo passa a ser o primeiro/E perde-se a noção da verdade [...] Sugiro que se rendam à Verdade/A verdade está na eternidade/Já nos dizia o maior dos mensageiros/Lá está a vida de verdade/Pois aqui somos apenas passageiros/A eternidade um dia viu/Que a Verdade estava ausente/Que ela adentrara o mundo vil/Que ela fora encarar a morte de frente/Que ela fora submeter-se ao tempo/Que num monte chamada Caveira/No meio de um martírio sangrento/ Trouxe a humanidade à vida verdadeira/Isto ficou comprovado no 
vazio do sepulcro/Pois da verdade não ficou ali retida/Ali não se pode ver dela nem o vulto/Ali a morte foi definitivamente vencida.

Após declamar o poema, o pastor Marcos aproveitou também fez uma homenagem à comunidade brasileira, que se uniu em torno das necessidades latentes do difícil momento. Seguindo a deixa do pastor, o padre Thiago pediu que essa união se perpetuasse.

Jiliane, a mãe de Kauane cantou a música 'Como viver sem você', de Marina de Oliveira, na beira do caixão, para homenagear a filha.

Ainda tento achar uma forma, De lançar a Dor no/Esquecimento, na saudade ver boas lembranças/Mas nem sempre aguento./Foi tão de repente o nosso amor, É dificil crer/Que tudo acabou,/Eu ainda tinha alguns segredos,/Ainda tinha sonhos de Amor./Hoje não me sinto tão jovem,/Para recomeçar, Como se existisse uma idade/Pra deixar de Sonhar,/Há perguntas dentro de mim, Nem o tempo vai explicar/Coisas que só Deus tem a resposta/N'Ele posso esperar./Mas hoje viver sem você,/Ainda é real demais pra ver,/Meu coração se partindo,/Quando a Metade era Você./Como viver sem você??/Preciso tanto aprender,/Hoje ainda não consigo,/ Só mesmo Deus pra me dizer./Ainda tento achar uma forma, De lançar a Dor no/Esquecimento, na saudade ver boas lembranças/ Mas nem sempre aguento./Foi tão de repente o nosso amor, É dificil crer/Que tudo acabou,/Eu ainda tinha alguns segredos,/ Ainda tinha sonhos de Amor./Hoje não me sinto tão jovem,/Para recomeçar, Como se existisse uma idade/Pra deixar de Sonhar,/ Há perguntas dentro de mim, Nem o tempo vai explicar/Coisas que só Deus tem a resposta N'Ele posso esperar./Mas hoje viver sem você,/Ainda é real demais pra ver,/Meu coração se partindo,/ Quando a Metade era Você./Como viver sem você??/Preciso tanto aprender,/Hoje ainda não consigo,/Só mesmo Deus pra me dizer./ Minha vida está no Centro da vontade do Senhor/Tudo que eu tenho é Dele, E você, Ele levou/Ele levou.../Mas hoje viver sem você,/Ainda é real demais pra ver,/Meu coração se partindo,/ Quando a Metade era Você./Como viver sem você??/Preciso tanto aprender,/Hoje ainda não consigo,/Só mesmo Deus pra me dizer./Mas hoje viver sem você,/Ainda é real demais pra ver,/Meu coração se partindo,/Quando a Metade era Você./Como viver sem você??/Preciso tanto aprender,/Hoje ainda não consigo,/Só mesmo Deus... 
É interessante observar que este ato de escrever e recitar um poema, ou mesmo de cantar uma música de terceiros, encontra-se com o que diz Wils (2009) quando ele sugere que, em situações de morte de crianças, é necessário uma linguagem diferente para dialogar com essa 'alma', na mesma 'altura' de compreensão, sendo a música e a poesia os meios de comunicação ideais para lidar com as implicações de dor que a morte de uma criança provoca, mas também para poder estabelecer, metaforicamente, um diálogo compreensível entre um adulto e uma alma infantil.

No final da missa de corpo presente, a mãe de Kaune retirou os brinquedos que estavam dentro do caixão e este foi fechado. A família então carregou o caixão em direção a saída da igreja e as pessoas acompanham em procissão atrás. $\mathrm{O}$ caixão foi colocado no carro do crematório e os balões brancos foram distribuídos para as pessoas. $\mathrm{O}$ carro com o corpo seguiu lentamente para o crematório, enquanto as pessoas soltaram os balões e bateram palmas.

$\mathrm{Na}$ Holanda, independentemente de a pessoa falecida e familiares serem ou não religiosos ${ }^{15}$, a maior parte dos uitvaarten (funerais - enterramentos/cremações) acontecem no ambiente dos begraafenisplaatsen (cemitérios e crematórios). Estes lugares são complexos que contem, em sua maioria, as salas dos 'wake' (velórios) - que são salas individuais fechadas, relativamente pequenas; a sala de recepção dos visitantes que chegam para os funerais; sala exclusiva de espera para os familiares próximos, o que permite privacidade aos familiares para expressarem de forma mais livre a sua dor; ao menos dois auditórios (de tamanhos diferentes) para a realização da cerimônia fúnebre. Sendo ou não uma cerimônia religiosa, no complexo funerário honlandês é valorizada a 'criatividade e individualização ritual', colocando o acento da cerimônia na personalidade e história do morto (Mathijssen \& Verhorst 2019; Moorselaar 2019; Blok et al 2018; Mathijssen 2017; Heessels 2012) ${ }^{16}$.

Qualquer que seja o lugar do uitvaart, igreja ou cemitério, há uma diferença que se estabelece, dependendo do corpo ser cremado ou en- 
terrado. No caso do enterramento, acompanha-se o cortejo do corpo até o túmulo, quando se realizam os ritos finais de enterramento; após encerrado o enterro, os familiares e participantes do cortejo retornam ao salão de recepção onde há uma espécie de confraternização, com o oferecimento de comidas e bebidas, sendo a comensalidade algo bastante importante dentro dos rituais fúnebres holandeses. No caso da cremação, costumeiramente, a família e os participantes da cerimônia fúnebre (ou missa de corpo presente), se dirigiam diretamente ao recinto de recepção para o momento da comensalidade, enquanto que os funcionários da funerária se encarregavam do corpo e de todo o processo de cremação; contudo, segundo Mathijssen, "cada vez mais os familiares querem levar o seu ente querido até o forno ou o local do forno" (2017:99), participando do momento per se da cremação, e só depois retornando para a sala de recepções, cumprindo o ritual da comensalidade.

Os pais e a tia de Kauane não quiseram seguir ao crematório e observar a cremação propriamente dita, , optando por não realizar mais essa etapa de ir até o local do forno crematório, pois segundo Jiliane, "era demais para ela". De acordo com a tia, Nelma, eles preferiam lembrar do corpo dela [Kauane], como era: a princípio, a tia não queria nem ver o corpo, pois queria "guardar só lembranças da menina viva”, mas na Igreja participou da missa de corpo-presente, refletindo a posteriori ter sido muito "bom", pois assim, ela pode aceitar melhor a morte da sobrinha.

Após a partida do carro com o corpo para cremação, as pessoas retornaram ao salão da igreja para tomar café ou chá com bolachas e bolo de cenoura, cumprindo aqui com o costume holandês da comensalidade. Jiliane e o padrasto de Kauane, antes de retornarem para a sua casa, abraçaram todas as pessoas presentes nesse momento para dizer obrigado. Jiliane disse: "Estava tudo muito lindo!"

Com o apoio financeiro conseguido através da mobilização da comunidade e amigos, Jiliane e o pai da criança retornaram ao Brasil, levando consigo as cinzas da criança. Segundo a Wet op de Lijkbezorging, 
as cinzas da pessoa falecida devem permanecer no mínimo 30 dias no crematório (Mathijssen 2017). Só após este prazo legal, os responsáveis podem buscar as cinzas que estão guardadas em uma urna ${ }^{17}$. Segundo a mesma legislação, atualmente é possível dispor quase que de maneira irrestrita das cinzas do morto, ou de dar um destino final às cinzas ${ }^{18}$.

Os pais de Kauane resolveram realizar um 'duplo funeral' para a filha na sua terra natal, voltando com as suas cinzas pouco depois dos rituais em Amsterdam. Dessa forma, a urna com as cinzas de Kauane foi liberada em tempo mais rápido do que o procedimento comum. Jilian e membros da paróquia Nossa Senhora de Fátima, que ajudaram com os procedimentos burocráticos ligados à funerário, conseguiram antecipar a liberação, com a justificativa da viagem para o Brasil. Nesse caso, o procedimento só durou 2 dias, e não o tempo normal regulado por lei. Eles receberam da funerária a urna lacrada, que foi levadaprimeiramente para casa de Jiliane. No dia 20 de julho, a mãe e o pai conseguiram retornar para o Brasil com as cinzas da filha. No dia 26 de julho, às 19h, ocorreu a missa e benção das cinzas de Kauane na igreja Católica Sagrado Coração de Jesus - Baianão, e no dia 27 de julho ocorreu o enterro das cinzas.

Dessa forma, cerca de uma semana após chegarem à cidade de Porto Seguro, na Bahia, foi organizado o 'duplo funeral' de Kauane, repetindo os mesmo rituais feitos na Holanda: velório e missa, com o enterro no cemitério local substituindo a cremação. Primeiro, a urna foi direto para igreja, pois na casa da avó não havia espaço suficiente para realizar o velório. Muitas pessoas estiveram presentes durante o velório realizado na igreja. Da igreja, saíram para o cemitério, onde fizeram a despedida diante do túmulo, a urna das cinzas substituindo o caixão. No cemitério, a urna foi depositada no centro da cova, sendo depois coberta com a terra, e finalmente cercada de flores; a cova transformando-se em uma "caminha”, nas palavras de Nelma ${ }^{19}$. Tanto na missa quanto no cemitério, havia algumas pessoas vestindo camisetas e com balões brancos, em uma repetição do ocorrido em Amsterdam. 
Realizar o enterro das cinzas na cidade de origem de Kaune foi um desejo de Jiliane, ligado principalmente ao ideal do retorno aos familiares, à avó e à terra de origem. Em especial, por causa da avó, que quando do ocorrido da morte achou difícil não poder ver o corpo da neta. Porém, desde o início do falecimento, as filhas foram conversando por what's app e telefone com ela, explicando a situação relativa às questões práticas e financeiras, quando por fim ela se resignou ao fato de que o corpo seria cremado. $\mathrm{O}$ 'duplo funeral' performado no Brasil é avaliado, assim, pelos parentes, como muito importante para aceitar a morte da menina. Sendo a criança enterrada no Brasil, a família sabe que ela "está lá no túmulo", e que eles podem visitar e lembrar-se dela, sempre.

\section{Concluindo em três tempos}

Os três casos apresentados ilustram bem o evento do 'duplo funeral'. Como dissemos no princípio deste artigo, a condição primeira para o surgimento do 'duplo funeral' é a de se estar em um contexto de migração transnacional, dentro dos três modelos propostos, em que a transnacionalidade é a condição primária do 'duplo funeral' porque ele depende da existência de dois espaços nacionais e duas temporalidades. Tanto no exemplo da morte em Londres, quanto da morte em Suriname e em Amsterdam, é a realização da duplicação dos funerais do morto em espaços e tempos diferentes que dá o contorno de um evento de 'duplo funeral'.

Aqui, a palavra-chave é a de duplicação. Nos diferentes 'complexos rituais fúnebres' (Reesink 2003), em que as ações podem se desenvolver também em espaços e tempos diferentes, como o citado 'segundo enterramento' (Hertz 1907), estas ações em diferentes espaços e tempos são partes do mesmo complexo ritual, aqui não há a ideia de duplicação, mas de etapas diferentes em tempos e espaços diferentes de um mesmo complexo ritual fúnebre. Contrariamente, na ideia do 'duplo funeral' o que vemos aqui é a sobreposição, $d u$ plicação, de ações rituais que estão - em certo sentido - descoladas 
umas das outras, que se repetem, quase como em um simulacro, ou podem requerer um conjunto de gestos rituais diferentes. Do ponto de vista das ações rituais, a duplicação do ritual implica que um é mais 'completo' ou 'complexo', enquanto que o outro é mais 'simples' e 'sintético'; da mesma maneira, o duplo funeral só faz sentido para parte das pessoas relacionadas ao morto. Em certo sentido, os dois conjuntos rituais são autônomos um do outro, mas ligados ao mesmo signo, ou referencial: o morto. Se abordarmos aqui uma perspectiva como a de Terence Turner (1991), poderíamos dizer que a dinâmica dos 'duplos rituais' é aquela de um campo metonímico que se desdobra em dois campos metafóricos, mas que pela relação contínua com o signo (corpo) se resolve em uma sinédoque, no sentido de permitir um entendimento simultâneo da duplicação do ritual.

Bastaríamos agora tentar compreender do porquê ou para quê o evento do 'duplo funeral'. Como dissemos, os 'duplos funerais' são estreitamente dependentes das expectativas dos sujeitos em relação ao que é um funeral 'bom', 'correto', 'suficiente', e isto em relação às crenças, práticas e moralidades dos sujeitos. Neste sentido, o que as ações rituais de Soyun Nessa, Lynn e Jiliane ${ }^{20}$ demonstram é que a não realização de um 'duplo funeral' revela a incompletitude - segundo suas expectativas (baseadas em suas crenças, afetos, práticas e moralidades) do ritual 'oficial'. O que se procura com os 'duplos funerais' é o sentido (subjetivo e objetivo) da realização, da satisfação, da completude. Tanto para os que (sobre)vivem, quanto para os que morrem.

\section{Notas:}

1 Curiosamente, outras ciências como teologia, psicologia e Comunicação têm se dedicado bastante a estas questões (p. ex. Bravo 2016).

2 Segundo a autora, termo nativo dado aos bengaleses migrantes que vivem/ viveram em Londres. 
3 A autora fez pesquisa em Londres e em Bangladeshi.

4 No contexto desses migrantes, segundo a autora, há diminuição enorme das redes de relações familiares/sociais extensas, ficando os imigrantes - sobretudo mulheres e crianças - dependentes da ajuda/cooperação da família nuclear.

5 Desh pode ser traduzida por 'terra natal' ou 'pátria'.

6 Angola, Cabo-Verde, Guiné-Bissau, Moçambique, São Tomé e Prince.

7 Reesink elaborou dois tipos-ideais para analisar estas distinções etnográficas: “a) 'modelo português-caboverdiano', diz respeito a aparentemente clássica migração coletiva, através de redes de parentesco ou vizinhança e que tendem a 'reproduzir' a comunidade de origem na localidade de destino, fechada e com pouca inclinação à integração com a sociedade hospedeira; nesse modelo, há uma tendência a um baixo índice de casamentos interétnicos, ao menos entre os da primeira geração; b) 'modelo brasileiro': referente à migração individualizada, com característica crescentemente feminina, baseada, sobretudo, em casamento entre imigrantes do sexo feminino e holandeses, parecendo ser esse o caso típico da migração brasileira à Europa" (2015:199).

8 Mantemos aqui os nomes originais porque se trata de dado público, tanto da comunidade católica, quanto na própria sociedade Holandesa, tendo em vista que a morte da criança foi anunciada na mídia, havendo toda uma campanha nas redes sociais por arrecadação de dinheiro para os custos dos funerais.

9 Baseada nos ritos de passagem de Van Gennep (1909), Moorselaar (2019) também analisa os ritos fúnebres na Holanda considerando este como um processo de três fases ou períodos.

10 Muitos holandeses também auxiliaram com dinheiro.

11 Segundo o que afirma Blok et al, mesmo quando é desejo dos familiares que o caixão seja aberto durante o ritual, isto não é permitido (2018:17); contudo, na prática é possível eventualmente ocorrer quebra da regra, como já observamos em outros funerais de pessoas falecidas holandesas: assim, após ou durante a primeira oração cantada, pode acontecer dos parentes mais próximos carregarem o caixão e o coloque em frente ao altar, onde permanece aberto durante a cerimônia, cercado por buquês de flores e fitas (para honrar o falecido), que serão colocados sobre o túmulo - em caso de enterramento, ou queimados junto com o cadáver - em caso de uma cremação. No caso específico de Kauane, acreditamos que isto foi possível por se tratar de uma cerimônia em um ambiente com predominância de imigrantes, o que lhes permitiu certa autonomia em organizar o ritual, com costumes diferentes, como é o caso do costume católico brasileiro de permanecer com o caixão aberto durante a missa de corpo presente, este sendo fechado apenas quando se encaminha definitivamente para o enterramento. Como a cerimônia de corpo presente de Kauane aconteceu em um ambiente 'brasileiro', dirigido por um padre de mesma tradição, o protocolo holandês foi quebrado.

12 Pode acontecer na Holanda, após ou durante a primeira oração cantada, que seja quando os parentes mais próximos carregam o caixão e coloque-o em frente ao altar, onde permanece durante a cerimônia cercada por buquês de flores e fitas, para 
honrar o falecido, que serão colocados sobre o túmulo depois de ter sido enterrado (ou queimados junto com o cadáver em caso de uma cremação).

13 Para uma introdução às práticas rituais fúnebres católicas na Holanda, ver Baar (2010) e Moorselaar (2019).

14 Em princípio, o que dá o caráter de 'missa' ao culto católico em geral é o fato de haver o momento da transfiguração do vinho e hóstia em o corpo e o sangue de Cristo, podendo ser realizada assim a comunhão. Isto só pode ser performado por um sacerdote, ou seja: um leigo ou mesmo seminarista não pode realizar a transfiguração. Neste sentido, os rituais sem a eucaristia são normalmente chamados de 'celebração'. Um leigo especialista (ministro da igreja, diácono ou seminarista, por exemplo) pode dar eucaristia, caso haja um recipiente considerado sagrado (p. ex.: sacrário) em que a hóstia e o vinho, consagrados em uma missa pelo sacerdote, possam aí ser guardados para futuras comunhões sem a presença necessária do sacerdote.

15 Segundo dados do CBS-Centraal Bureau voor Statistiek (Escritório Central de Estatística da Holanda), em 2017, dos holandeses maiores de 15 anos, 51\% se declararam 'Sem Religião'; 24\% se declararam 'Católicos'; 15\% 'Protestantes' ligados a igrejas reformadas da Holanda; $5 \%$; $6 \%$ de 'outros', dos quais 5\% declarando-se alguma forma classificada como 'Evangélicos' pelo CBS (Mathijssen \& Verhorst 2019).

16 A maior parte dos pesquisadores holandeses, apesar de citarem a regularidade nos funerais, parece construir suas análises de maneira extremamente êmica, colocando maior força e energia na ideia de 'funerais personalizados', 'rituais criativos', 'ritualidade em construção', repetindo de maneira quase irrefletida a teoria nativa de 'rituais sempre novos, criativos e personalizados'. Para uma discussão crítica mais aprofundada sobre o assunto, ver Reesink 2020.

17 Contudo, é possível fazer exceç̃os em casos excepcionais, como por exemplo, em casos de cinzas de imigrantes que se pretende retornar a sua terra natal.

18 De acordo com Moorselaar (2019) e Heessels (2012), existem três principais práticas relacionadas ao destino das cinzas na Holanda: uma, é o jogar as cinzas no 'campo das cinzas' dos crematórios e/ou cemitérios, lugar destinado exclusivamente para este ato; a segunda, a de jogar as cinzas em algum lugar especial e de relevância para o morto (como por exemplo, no mar); a terceira, é o de marcar um lugar especial onde as cinzas permanecem em suas urnas, podendo ser um 'altar' em casa, ou uma espécie de túmulo disponibilizado em cemitérios. Há ainda a prática de dividir as cinzas da pessoa entre os parentes; ou de colocar parte das cinzas em joias que são usadas pelos familiares.

19 A tia não esteve presente fisicamente desses rituais, participando através de transmissão online.

20 Chamamos a atenção aqui que não deve ser por acaso que se trata de mulheres. Consideramos que a questão de gênero aqui tem um papel importante. Contudo, não temos dados suficientes ainda para fazer uma análise mais consistente a partir desta chave de interpretação. 


\section{Referências:}

BAAR, Mirjam de (2010). “'Wat maakt youw uitvaart uniek?' Over kerkelijke en vrije afscheidsrituelen rond dood en begraven”. In KROESEN, J., KUIPER, Y. \& NANNINGA, P. (eds.): Religie en cultuur in hedendaags Nederland: observaties en interpretaties, pp. 35-43. Assen: Van Gorcum.

BLOK, L. et al. 2018. Dood op maat Over rituelen en herdenkingen rondom overlijden. Relatório de Pesquisa. Nijmegen: Radboud Universiteit.

BLOCH, M. \& PARRY, J. 1982. Death and Regeneration of Life. Cambridge/ London/New York: Cambridge University Press.

BRAVO, Vanessa. 2017. "Coping with dying and deaths at home: how undocumented migrants in the United States experience the process of transnational grieving". Mortality, 22(1):33-44.

CAPPERS, Wim. 2014. "Aan deze zijde van de dood. Funeraire componenten van seculariserende cultuurlandschappen in Nederland 1576-2010”. Jaarboek voor liturgieonderzoek, 30:263-276.

CARNEIRO DA CUNHA, Manuela. 1978. Os Mortos e os Outros: uma análise do sistema funérario e da noção de pessoa entre os indios Krahó. São Paulo: Hucitec.

CHAUMEIL, Jean-Pierre. 1997. "Les Os, les Flûtes et les Morts : mémoire et traitement funéraire en Amazonie”. Journal de la Société des Américanistes, 83:83-110.

DANFORTH, Loring M. 1982. The Death Ritual of Rural Greece. Princeton: Princeton University Press.

FABIAN, Johannes. 1972. "How Others Die - Reflections on the Anthropology of Death”. Social Research, 39(3):543-567.

GARDNER, Katy. 20020 "Death of a migrant: transnational death rituals and gender among Britsh Sylhetis”. Global Networks, 2(3):191-204.

HEESSELS, Meike. 2012. "Het thuisbrengen van de doden in Nederland". Jaarboek voor liturgieonderzoek, 28:267-275.

HERTZ, Robert. 1907[1905-1906]. “Contribution à une Étude sur la Représentation Collective de la Mort”. L’Année Sociologique, 10:48-137.

MARTINS, Andrea D. 2012. "Relocalização da Religião em Contexto Transnational: o caso da igreja católica de língua portuguesa em Haia, Holanda”. In ORO, A., STEIL, C. \& RICKLI, J. (eds.): Transnationalização religiosa: fluxos e redes, pp. 145-156. São Paulo: Editora Terceiro Nome.

MATHIJSSEN, B. \& VENHORST, C. 2019. Funerary Practices in The Netherlands. Groningen/ Bingley: University of Groningen/ Emerald Publishing Limited.

MATHIJSSEN, Brenda. 2017. "Zin- en Vormgeven aan de Dood Rituele Praktijken en Situationele Geloofsvoorstellingen van Nabestaanden in Nederland”. Yearbook for Ritual and Liturgical Studies, 33:92-104.

METCALF, P. \& HUNTINGTON, R. 1992. Celebrations of Death: the anthropology of mortuary ritual. Cambridge: Cambridge University Press. 
MOORSELAAR, Thijs van. 2019. De Nederlandse Uitvaartcultuur: Een antropologische kijk op de betekenis van crematie-as en de relatie tussen de levenden en de doden. Dissertação de Mestrado. Leiden: Leiden Universiteit.

OLWIG, Karen. 2009. "A Proper Funeral: contextualizing community among Caribbean migrants". Journal of the Royal Anthropological Institute, 15(NS):520537.

PIJL, Ivon van der. 2016. "Death in the family revisited: ritual expression and controversy in a Creole transnational mortuary people”. Ethnography, $17(2): 147-167$.

REESINK, Mísia Lins. 2003. Les Passages Obligatoires: cosmologie catholique et mort dans le quartier de Casa Amarela, à Recife (Pernambuco - Brésil). Tese de Doutorado. Paris: École des Hautes Études em Sciences Sociales. . 2015. "Minha Língua, Minha Fé, Minha Igreja: ser católico estrangeiro de língua portuguesa na Holanda". In RODRIGUES, D. \& ORO, A. (eds.): Transnacionalização religiosa: religiões em movimento, pp. 197-224. Porto Alegre: Cirkula. 2016. Morte, Católicos, Imaginário: rituais e representações de morte em Casa Amarela (Recife). Recife: EdUFPE. . 2018. "Imigrantes Oriundos dos PALOP e Comunidades Católicas de Língua Portuguesa na Holanda”. In MOTTA, A., LOBO, A. \& TRAJANO FILHO, W. (eds.): África Fora de Casa, pp. 1-30. Brasilia/Recife: ABA Publicações/EDUFPE.

. 2020. Primeiras reflexões sobre rituais fúnebres a partir dos Países Baixos. Conexões com o Brasil em tempos de Covid-19. Trabalho apresentado na "Live da Revista M", junho.

RODRIGUES, José Carlos. 1983. Tabu da Morte. Rio de Janeiro: Achiamé.

THOMAS, Louis-Vincent. 1975. Anthropologie de la Mort. Paris: Payot.

TURNER, Terence. 1991. “'We Are Parrots', 'Twins Are Birds': Play of Tropes as Operational Structure". In FERNANDEZ, J. (ed.): Beyond Metaphor: The Theory of Tropes in Anthropology, pp. 121-158. Stanford: University of Stanford Press.

TURNER, Victor. 1980. "Social Dramas and Stories about Them". Critical Inquiry, 7(1): $141-168$

VAN GENNEP, Arnold. 1969[1909]. Les Rites de Passage: études systématiques des rites... . Paris: Mouton \& Co/ Maison des Sciences de l'Hommes.

WILS, Jean-Pierre. 2009. "Rituelen van de dood - Een verkenning". Tijdschrift voor Theologie, 49(3):225-236.

Abstract: In the anthropological literature there are few cases of an ethnographic analysis of the phenomenon of death in transnational contexts, notwithstanding the fact that anthropology has been one the social scienc- 
es that dedicated the most attention to death. Here we seek to address this gap by presenting a comparative analysis of three different situations of deaths that occurred in transnational contexts. The first case concerns Bengal immigrants in England, described by the British anthropologist Kathy Gardner; the second occurred in Surinam, described by the Dutch anthropologist Ivon van der Pijl; the third case comes from the Netherlands, amongst Brazilian migrants, and concerns our own research. In this way we seek to identify differences and approximations between the three cases, concluding that, in certain transnational contexts, the occurrence of the death of a migrant induces the families and/or communities to actions which we categorize and problematize as a 'double funeral' ritual.

Keywords: Double funerals, Comparison, Death, Transnationalism, Migration.

Recebido em maio de 2020.

Aprovado em julho de 2020. 